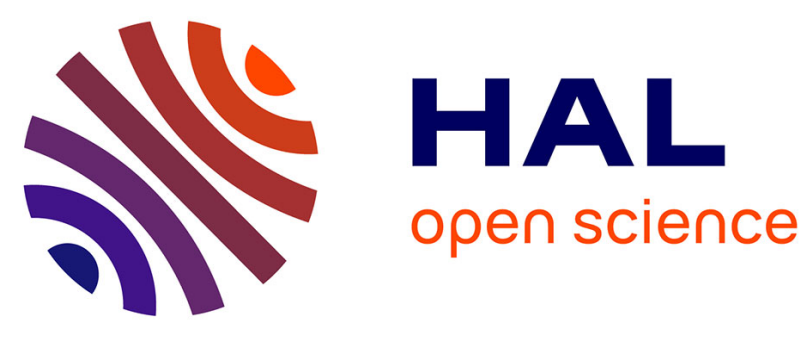

\title{
The Dutch Eating Behavior Questionnaire: Further psychometric validation and clinical implications of the French version in normal weight and obese persons
}

Paul Brunault, Isabelle Rabemampianina, Gérard Apfeldorfer, Nicolas Ballon, Charles Couet, Christian Réveillère, Philippe Gaillard, Wissam El-Hage

\section{To cite this version:}

Paul Brunault, Isabelle Rabemampianina, Gérard Apfeldorfer, Nicolas Ballon, Charles Couet, et al.. The Dutch Eating Behavior Questionnaire: Further psychometric validation and clinical implications of the French version in normal weight and obese persons. La Presse medicale, 2015, 44 (12), pp.e363372. 10.1016/j.lpm.2015.03.028 . hal-01296358

\section{HAL Id: hal-01296358 https://hal.science/hal-01296358}

Submitted on 31 Mar 2016

HAL is a multi-disciplinary open access archive for the deposit and dissemination of scientific research documents, whether they are published or not. The documents may come from teaching and research institutions in France or abroad, or from public or private research centers.
L'archive ouverte pluridisciplinaire HAL, est destinée au dépôt et à la diffusion de documents scientifiques de niveau recherche, publiés ou non, émanant des établissements d'enseignement et de recherche français ou étrangers, des laboratoires publics ou privés. 
Title: The Dutch Eating Behavior Questionnaire: further psychometric validation and clinical implications of the French version in normal weight and obese persons.

Short title: French version of the Dutch Eating Behavior Questionnaire.

Titre: La version française du questionnaire 'Dutch Eating Behavior' : validation psychométrique complémentaire chez les personnes normo-pondérales et obèses et implications pour la pratique clinique. Auteurs : Paul Brunault ${ }^{1,2,3,4}$, Isabelle Rabemampianina ${ }^{5}$, Gérard Apfeldorfer ${ }^{6}$, Nicolas Ballon ${ }^{1,2,4,7,8}$, Charles Couet $^{4,8,9,10}$, Christian $\quad$ Réveillère $^{3}, \quad$ Philippe $\quad$ Gaillard $^{2,7,8}, \quad$ Wissam $\quad$ El-Hage $^{2,7,8}$

${ }^{1}$ CHRU de Tours, Équipe de Liaison et de Soins en Addictologie, Tours, France

${ }^{2}$ CHRU de Tours, Clinique Psychiatrique Universitaire, Tours, France

${ }^{3}$ Université François Rabelais de Tours, Département de Psychologie, EA 2114 «Psychologie des Âges de la Vie », Tours, France

${ }^{4}$ CHRU de Tours, Centre Spécialisé pour la prise en charge de l’Obésité sévère, Tours, France

${ }^{5}$ APHP, Hôpital Ambroise Paré, Unité fonctionnelle Équipe de Liaison et de Soins en Addictologie et

Psychiatrie de Liaison, Boulogne, France

${ }^{6}$ Groupe de Réflexion sur l'Obésité et le Surpoids, 28 rue Ponthieu, Paris, France

${ }^{7}$ UMR INSERM U930 ERL, Tours, France

${ }^{8}$ Université François Rabelais de Tours, Tours, France

${ }^{9}$ CHRU de Tours, Service de Médecine Interne-Nutrition, Tours, France

${ }^{10}$ Inserm UMR 1069, Université François Rabelais de Tours, Tours, France

Corresponding author : Paul Brunault ; CHRU de Tours, Équipe de Liaison et de Soins en Addictologie, 2 boulevard Tonnellé, 37000 Tours, France ; e-mail: paul.brunault@univ-tours.fr; Téléphone : 02-47-47-80-43; Fax: 02-47-47-84-02

Brunault $^{1,2,3,4}$, Isabelle Rabemampianina ${ }^{5}$, Gérard Apfeldorfer ${ }^{6}$, Nicolas Ballon ${ }^{1,2,4,7,8}$, Charles Couet ${ }^{4,8,9,10}$, Christian Réveillère ${ }^{3}$, Philippe Gaillard ${ }^{2,7,8}$, Wissam El-Hage

This is the postprint version (final draft post refereeing) of the following article: "Brunault P., Rabemampianina I., Apfeldorfer G., Ballon N., Couet C., Réveillère C., Gaillard P., El-Hage W. (2015). The Dutch Eating Behavior Questionnaire: further psychometric validation and clinical implications of the French version in normal weight and obese persons. Presse Medicale; 44(12 Pt 1):e363-72. 10.1016/j.Ipm.2015.03.028. Epub 2015 Nov 17.”, which has been published in final form at: http://www.sciencedirect.com/science/article/pii/S075549821500384X 


\section{ABSTRACT:}

Objectives: This study (1) tested the psychometric properties of the French version of the Dutch Eating Behavior Questionnaire (DEBQ) for normal weight and obese patients; (2) determined the factors associated with each DEBQ score: emotional eating (eating in response to emotional arousal states such as fear, anger or anxiety), externality (eating in response to external food cues such as sight and smell of food), and restrained eating behavior/cognitive restraint (conscious efforts to limit and control dietary intake); and (3) determined how to interpret the results from this scale to guide clinical practice.

Methods: Between January 2009 and April 2009, we assessed non-paired normal weight persons $(\mathrm{n}=74)$ and all consecutive obese patients consulting in the Nutrition ward of the University Hospital of Tours ( $\mathrm{n}=75$; including bariatric surgery patients) using the DEBQ. We tested the scale's factor structure using a factor analysis for ordinal data and internal consistency for each DEBQ dimension.

Results: Our results supported a three-factor structure for both normal weight and obese patients. The Cronbach's alpha coefficients were excellent for emotional eating and externality $(\alpha \geq 0.90)$ and good for cognitive restraint $(\alpha \geq 0.81)$. The emotional eating and cognitive restraint scores were higher for women $(\mathrm{p}<0.001)$ and obese patients $(\mathrm{p}<0.05)$. Higher cognitive restraint was associated with higher current and previous BMI $(\mathrm{p}<0.01)$. For patients who had bariatric surgery, higher length of time since surgery was significantly associated with higher externality $(\rho=0.359 ; p \leq 0.05)$ and marginally associated with higher cognitive restraint $(\rho=0.294 ; p=0.10)$ and higher emotional eating $(\rho=0.302 ; p=0.10)$.

Conclusions: Our results support a three-dimensional factor structure for the French version of the DEBQ for normal weight and obese patients. We propose the chance to change hypothesis to explain results for bariatric surgery patients: patients experience a beneficial but transient decrease in externality, emotionality and cognitive restraint, and this period of time gives the patient a chance for cognitive, behavioral and emotional change. This critical period should be well prepared before surgery to improve the patient's postoperative success, by tackling each factor that could diminish the chances for success as soon as possible (e.g., early screening and treatment for psychiatric disorders).

Keywords: Psychometrics; eating disorders; obesity; bariatric surgery; Dutch Eating Behavior Questionnaire. 


\section{RÉSUMÉ :}

Objectifs : Ce travail avait trois objectifs : (1) tester les propriétés psychométriques de la version française du Dutch Eating Behavior Questionnaire (DEBQ) auprès de personnes normo-pondérales et obèses ; (2) rechercher quels sont les facteurs associés aux trois dimensions de l'échelle : émotivité alimentaire (alimentation secondaire à des stimuli émotionnels), externalité (alimentation secondaire à des stimuli alimentaires) et restriction cognitive (intention d'avoir un contrôle pondéral en contrôlant son alimentation); et (3) : déterminer comment cet outil peut être utilisé pour guider les interventions thérapeutiques.

Méthodes : Entre janvier 2009 et avril 2009, nous avons administré le DEBQ à des patients normo-pondéraux $(n=74)$ et tous les patients obèses consultant de manière consécutive dans le service de Médecine Interne Nutrition du CHRU de Tours ( $\mathrm{n}=75$, dont des patients opérés de chirurgie bariatrique). Nous avons étudié la structure factorielle de l'échelle (analyses factorielles basée sur des corrélations polychoriques du fait du caractère ordinal des données) et la consistance interne de chaque dimension du DEBQ.

Résultats : le DEBQ possède une structure tridimensionnelle comparable dans les deux populations. Les coefficients alpha de Cronbach étaient excellents pour l'émotivité alimentaire et l'externalité $(\alpha \geq 0,90)$ et bon pour la restriction cognitive $(\alpha=0,81)$. L'émotivité alimentaire et la restriction cognitive étaient plus élevés chez les femmes $(\mathrm{p}<0.001)$ et chez les patients obèses $(\mathrm{p}<0,05)$. Une plus forte restriction cognitive était associée à un IMC actuel ou passé plus élevé $(\mathrm{p}<0,01)$. Chez les patients opérés d'une chirurgie bariatrique, plus le temps après la chirurgie augmentait, plus l'externalité augmentait $(\rho=0,359 ; p \leq 0,05)$ et plus l'émotivité alimentaire $(\rho=0,302 ; p=0,10)$ et la restriction cognitive $(\rho=0,294 ; p=0,10)$ avaient tendance à augmenter.

Perspectives : Nos résultats confirment la structure tridimensionnelle de la version française du DEBQ chez les patients obèses et normo-pondéraux. Nous proposons ici l'hypothèse de l'opportunité du changement pour expliquer les résultats obtenus chez les patients opérés d'une chirurgie bariatrique: immédiatement après chirurgie, les patients expérimenteraient une diminution transitoire des niveaux d'externalité, d'émotivité alimentaire et de restriction cognitive, permettant alors au patient d'être dans une période propice à des changements cognitifs, comportementaux et émotionnels. Cette période importante doit être préparée en amont de la chirurgie afin d'optimiser la réussite du projet chirurgical, en agissant de manière précoce sur tous les facteurs susceptibles de diminuer les chances de succès (par exemple, en dépistant et en traitant de manière précoce les troubles psychiatriques).

Mots-clés: Psychométrie; troubles du comportement alimentaire; obésité; chirurgie bariatrique; Dutch Eating Behaviour Questionnaire. 


\section{INTRODUCTION}

Obesity, defined as a Body Mass Index (BMI) $\geq 30 \mathrm{~kg} / \mathrm{m}^{2}$, is a major health problem in Western countries. In France, obesity's prevalence rate doubled over the past 15 years, as approximately 7 million adults are obese (15\% of the population) [1]. In addition, obesity is a risk factor for psychiatric disorders [2] and is associated with a decrease of more than 5 years in life expectancy [3]. Some authors have hypothesized that the recent increase in obesity might be partly accounted for by eating disorders (ED), such as binge eating disorder (i.e., recurrent binge eating without the regular use of compensatory measures to counterweight gain) [4] or food addiction [5], which we can now assess in English-, German- and French- speaking countries [6-8]. To explain why some patients gain weight and experience dyscontrol in their eating behavior, three theories have been proposed: psychosomatic theory (i.e., emotional eating), externality theory and cognitive restraint theory [9]. According to Bruch and Kaplan's psychosomatic theory [10,11], weight gain and dyscontrol over eating can be explained by emotional eating, which is an increase in food intake in response to an internal state of emotional arousal, such as anxiety or depression. According to Schachter and Rodin's externality theory $[12,13]$, weight gain and dyscontrol over eating can be explained by external eating, which is an increase in food intake in response to external food cues rather than to an internal state of hunger or satiety. This theory is supported by the increased availability of food and a progressive increase in fat and sugar content since the 1970s in Western countries [14]. Finally, weight gain and dyscontrol over eating can also be explained by cognitive restraint theory, which Herman and Polivy defined as an intentional effort to achieve or maintain a desired weight through reduced caloric intake [15]. According to this theory, people who develop cognitive restraint are at a high risk for the development of eating disorders.

The Dutch Eating Behavior Questionnaire (DEBQ) is an internationally recognized gold standard instrument for simultaneously assessing the three cognitive, emotional and behavioural dimensions of eating behavior $[9,16]$. Other questionnaires such as the Three Factor Eating Questionnaire, revised form (TFEQ-R) $[17,18]$ can also be used to assess the dimensions associated with eating behaviour.Until now, only one study has assessed the psychometric properties of the French version of the DEBQ (DEBQf) [16]. According to Lluch et al. [16], the DEBQf has a three-factor structure that is aligned with the three theoretical dimensions, with good to excellent internal consistency for each dimension [16]. However, Lluch et al. [16] only focused on the factor structure and internal consistency of the DEBQ for obese patients and did not examine the factor structure of the scale for normal weight persons. In addition, very few studies have determined the factors associated with each DEBQ dimension. 
Because reliability is a necessary, but not sufficient, component of validity [19], evidence should be accumulated from multiple sources - e.g., multiple populations - to support the validity of inferences drawn from a given instrument's scores. No studies investigated the construct validity of the DEBQf in normal weight persons and bariatric surgery patients (Lluch et al.'s study included only 15 obese patients [16]). In addition, polychoric correlations should be used to test a factor structure when the data are ordinal [20], but no study has used polychoric correlations to test the DEBQf's factor structure. Finally, few studies have assessed the factors associated with each DEBQ dimension, and we lack data on how the scores from the three DEBQ dimensions can be used in clinical practice to guide therapeutic interventions for patients who experience dyscontrol over eating and weight gain. Indeed, a better understanding of the dimensions associated with weight gain (i. e. emotionality, externality and/or cognitive restraint) for a given patient could help clinicians choose the best tailored interventions. Such an approach aims to improve the patient's ability to adjust to follow-up and benefit from intervention. For bariatric surgery patients, this approach could help the patients be better prepared for bariatric surgery and postoperative follow-up.

One aim for this study was to test the construct validity of the DEBQf for both normal weight and obese persons. We hypothesized that the three-factor structure initially described in obese patients [16] would also be found in normal weight patients. Our other objectives were to determine the variables associated with each DEBQ subscale (cognitive restraint, emotionality and externality) and how the scores for each DEBQ dimension could be interpreted to guide practical and therapeutic interventions in clinical practice.

\section{METHODS}

\section{Participants}

We included male and female normal weight persons who were medicine residents or physicians working in the University Hospital Centre of Tours, Francea. Normal weight patients were recruited between January 2009 and April 2009 based on a mailed questionnaire sent to medicine residents and physicians working in the ward and in psychiatry in the University Hospital of Tours. Obese patients were recruited in the Nutrition ward of the University Hospital Centre of Tours: we enrolled all consecutive male and female obese patients who consulted in this ward for their obesity (i.e., after bariatric surgery or for their nutritional or medical follow-up) between January 2009 and April 2009. We included only patients who accepted to participate and who were able to understand French. We did not paired the two groups. Patients were asked to complete the self-administered 
questionnaires shortly after their consultation. The data collection was conducted as part of a medical thesis of a resident in psychiatry and was supervised by physicians in charge of the follow-up of the obese patients.

Data collection was performed by the resident in psychiatry in charge of the study. We ensured privacy and confidentiality in the data collected from the participants both during and after the conduct of the study. We entered and analyzed all information anonymously.

\section{Measures}

\section{Dutch Eating Behavior Questionnaire}

This 33-item, self-administered questionnaire was designed by Van Strien et al. Ratings are made on a 5-point Likert scale [9]. The initial factor structure of the DEBQ was composed of three independent dimensions: cognitive restraint (10 items), externality (10 items) and emotionality (13 items). The emotionality dimension includes diffuse emotionality and defined emotionality subscales. We used the French version, which was originally developed by Lluch et al. [16].

\section{Statistical analyses and ethical issues}

Analyses were conducted using the $\mathrm{R}$ statistical software version 2.15 .2 [21]. We used the psych package designed by William Revelle [22] and the polycor package [23], which provided the polychoric correlations to analyze the DEBQ items because it is a 5-point ordinal scale. To test the scale's factor structure for each population (normal weight and obese patients), we conducted a factor analysis with varimax rotation [20]. For each population, we determined the number of factors to extract by examining the scree plot (i.e., the eigenvalues and Cattel's scree test), Kaiser's rule (i.e., we kept factors with a minimal eigenvalue of 1) and Horn's parallel analysis test. We assessed internal consistency using Cronbach's $\alpha$ internal consistency coefficient. We assessed the scale's construct validity by determining which variables were associated with each DEBQ subscale score, i.e., emotionality, externality and cognitive restraint. Nonparametric tests were used because the distributions were non-normal. All analyses were 2-tailed, and p-values less than 0.05 were considered statistically significant. Our study did not require institutional review board approval because it was not considered biomedical research under French law; however, it followed the tenets of the Declaration of Helsinki.

\section{RESULTS}

We included 74 normal weight persons (BMI between 18.5 and $25 \mathrm{~kg} / \mathrm{m}^{2}$ ) and 75 obese patients. Characteristics of our study populations are in Table I. 


\section{Internal consistency and factor structure for normal weight persons (Table II)}

The scree plot and Horn's parallel analysis test both suggested a three-factor structure (Figure 1 and Table II). This three-factor structure was the same as the three-factor structure of the DEBQ's original version and was composed of three factors that explained $52 \%$ of the variance: emotionality $(19.1 \%$ of the variance explained; $\alpha=0.96)$, cognitive restraint ( $18.6 \%$ of the variance explained; $\alpha=0.89)$ and externality $(14.2 \%$ of the variance explained; $\alpha=0,92$ ). For emotionality, factor loadings were greater than 0.58 for all items (items $1,5,10,13,16$, 20, 23, 25, 30, 32; Table II). For cognitive restraint, factor loadings were greater than 0.59 for all items (items 4 , $7,11,14,17,19,22,26,29,31)$. For externality, factor loadings were greater than 0.38 for all items (items 2,3 , $6,8,9,12,15,18,21,24,27,28,33)$.

\section{Internal consistency and factor structure for obese patients (Table III)}

The scree plot and Horn's parallel analysis test both suggested a three-factor structure (Figure 2 and Table III) for obese patients. This three-factor structure was also the same as the three-factor structure of the DEBQ's original version and was composed of three factors (55.3\% of the variance explained); emotionality (26.8\% of the variance explained; $\alpha=0.97)$; externality (17.2\% of the variance explained; $\alpha=0.90)$; and cognitive restraint (11.3\% of the variance explained; $\alpha=0.81)$. For emotionality, factor loadings were greater than 0.58 for all items (items $1,3,5,8,10,13,16,20,23,25,30,32$; Table III). For externality, factor loadings were greater than 0.48 for all items $(2,6,9,12,15,18,21,27,28,33)$. For cognitive restraint, factor loadings were greater than 0.41 for all items (items 4, 7, 11, 14, 17, 19, 22, 24, 26, 29, 31), except item $24(0,24)$.

Factors associated with cognitive restraint, emotionality and externality scores in the whole population (Table IV)

Cognitive restraint scores were higher for women $(\mathrm{p}<0.001)$, older people, people who had a higher current BMI (especially obese persons), and those with a history of important weight loss. Emotionality scores were higher for women $(\mathrm{p}<0.001)$ and people who had a higher current BMI. Externality scores were higher for younger people and people who had a lower current BMI.

Factors associated with cognitive restraint, emotionality and externality scores in bariatric surgery patients

Cognitive restraint scores were higher for bariatric surgery candidates than they were for patients who underwent bariatric surgery $(\mathrm{p}<0.001)$. For patients who underwent surgery, as time since surgery increased, externality increased $(\rho=0.359 ; p \leq 0.05 ;$ Supplemental Figure 1), cognitive restraint increased $(\rho=0.294 ; p=0.10$; Supplemental Figure 2), and emotionality tended to increase $(\rho=0.302 ; p=0.10 ;$ Supplemental Figure 3$)$. 


\section{DISCUSSION}

We found that the DEBQf had a three-factor structure for both normal weight and obese patients, including bariatric surgery patients. For patients who underwent bariatric surgery, as time since surgery increased, externality increased, and emotionality and cognitive restraint tended to increase. This finding suggests that bariatric surgery could have a beneficial but transient effect on these dimensions. To explain these results, we propose the chance to change hypothesis, which postulates that the early postoperative period is critical for patients because it gives the patient an opportunity to change his eating behaviour. At the end of this discussion, we elucidate how the scores from each of the three DEBQ dimensions can guide practical and therapeutic interventions in clinical practice.

\section{DEBQ's construct validity}

We demonstrated that the DEBQf had a three-factor structure with good to excellent internal consistencies for all subscales for both obese and normal weight patients. For normal weight patients, we found a factor structure very close to that originally found by Lluch et al. [16]. Only items 8 and 28 differed between the two studies. The factor structure for obese patients was also very close to that for normal weight patients because only items 3, 8 and 24 differed between the populations. These items were associated with several dimensions of the DEBQ. For both populations, we found a good to excellent internal consistency for each DEBQ subscale, which suggests a robust three-factor structure. There were, however, minor differences between the populations: for normal weight people, the three dimensions explained nearly the same percent of the variance $(19.1 \%, 18.6 \%$ and $14.2 \%$ ), while for obese patients, the emotionality and externality dimensions explained a much higher proportion of the variance $(26.8 \%$ and $17.2 \%$, respectively) than did cognitive restraint $(11.3 \%)$. These results suggest that the three dimensions should be considered for normal weight persons; the dimensions of emotionality and externality are particularly important for obese patients. This validation study paves the way for future research with either normal weight or obese persons to determine whether the externality, emotionality and cognitive restraint DEBQ dimensions are associated with quality of care variables such as improved weight loss, psychiatric comorbidity and health-related quality of life.

Our secondary objective was to identify variables that were associated with each DEBQ dimension. The finding that women had higher emotionality and cognitive restraint scores is consistent with previous studies that found higher prevalence rates for eating and mood disorders for women compared with men [24,25]. We confirmed that cognitive restraint was higher for patients who had current or past overweight or obesity than for the overall population. Because cognitive restraint remained high even among people who had a history of 
important weight loss, this finding confirms that obesity is a chronic disease that should be treated using a longterm rather than short-term approach [26]. Because cognitive restraint and emotionality might be risk factors for a future eating disorder, these patients could benefit from cognitive and behavioral interventions that are adapted to their level of cognitive restraint and emotionality so they can achieve sustainable weight loss. Such interventions should indeed take into account that a too large decrease in cognitive restraint may be associated with weight regain [27], while a too large increase in cognitive restraint may be associated with eating disorders [15].

\section{Clinical implications for bariatric surgery patients}

Findings observed for bariatric surgery patients suggest that bariatric surgery may lead to a beneficial but transient decrease in externality (e.g., a transient decrease in food intake in response to external food cues), and in emotionality and cognitive restraint, with decreases that washed out over time. In line with these results, we can propose the chance to change hypothesis to explain how bariatric surgery can improve weight and eating behaviour and why bariatric surgery may lead to long-term changes in some patients, and not in others. This hypothesis postulates that bariatric surgery patients experience a beneficial but transient decrease and recovery in their levels of externality, emotionality and cognitive restraint, and that this period of time gives the patient a chance for cognitive, behavioral and emotional change (i.e., better regulation of food intake during the postoperative period). We can assume that a combination of physiological and psychological changes (i.e., first better regulation of food intake combined with a long-lasting motivation for change) is necessary to achieve sustainable improvement in eating disorders and weight. If the chance to change hypothesis were confirmed, it would suggest that the early postoperative period would be a critical period during which the patient's behavioral, cognitive and emotional changes should be systematically addressed, reinforced and supported by clinicians.

\section{Clinical and therapeutic implications for obese patients}

Despite these limitations, this study supports the DEBQ as a reliable questionnaire that physician could use in clinical practice to assesstow

the dimensions of externality, emotionality and cognitive restraint, which are three important clinical dimensions for obese patients. The DEBQ may also have important therapeutic implications for clinical practice. Using the DEBQ for a patient referred for obesity or eating disorder can help determine the most prevailing dimension(s) associated with its eating behavior and thus which therapeutic interventions should be chosen. Adequate interpretations of the DEBQ's scores could be used as a tool to complement the clinical interview and 
guide clinicians toward the best tailored interventions for a given patient. For patients who experience high externality (i.e., food intake in response to external food cues), therapeutic interventions that decrease the saliency of external food cues could be useful. This type of intervention could increase patients' awareness of physiological sensations and improve their ability to distinguish between situations in which food intake occurs in response to external food cues or in response to an internal state of hunger or satiety. In such situations, examples of therapeutic interventions include cognitive behavioral therapy focused on problematic situations that will improve patients' sense of control or psychotropic drugs that decrease craving for specific foods. For patients who report high emotionality (i.e., food intake in response to an internal state of emotional arousal), therapeutic interventions should target the cognitive and emotional factors associated with food intake, especially anxiety and depression. In these situations, psychotherapy can improve the patients' ability to understand and cope with anxiety and depression. Finally, for patients with high cognitive restraint, a gradual decrease in diet-induced cognitive restraint could minimize the long-term risks associated with sustainable cognitive restraint, e.g., increased risk for acute disinhibition toward food intake and for eating disorders that will negatively impact long-term weight and quality of life evolution. To help a patient with high cognitive restraint who seeks weight loss, one therapeutic goal is to find the balance point between tolerance and constraint, that is, between obligation to adhere to a permanent treatment and an ideal weight loss [28]. In all cases, eating disorder management for obese patients should systematically include a prior and in-depth functional analysis to understand the underpinnings of the eating disorder/behavior and the patient's distress. Because there is great variability in clinical presentations, therapeutic interventions should be tailored on a caseby-case basis with a common objective: restore the nutritional and relational purposes of the eating behaviour [28] and improve the patient's quality of life. To achieve this therapeutic goal, clinicians should systematically screen for and treat associated psychiatric comorbidities because they are prevalent in patients with eating disorders and associated with decreased quality of life [29,30].

\section{$\underline{\text { Limitations }}$}

Our study had several limitations. First, our study's cross-sectional design precludes testing our chance to change hypothesis, as it may only be tested in a longitudinal study. Future studies should examine the DEBQ's construct validity for other clinical populations (e.g., patients with eating disorders such as binge eating disorder and bulimia nervosa) with larger sample sizes to determine whether the factor structure is the same for these populations. 


\section{Conclusion}

In conclusion, this study suggests that the DEBQf is a valid and reliable questionnaire that can be used in both normal weight and obese persons, especially in obese patients who desire to lose weight or be candidate for a bariatric surgery. We believe that this questionnaire might be useful to determine what are the dimensions associated with eating behavior in patients with other eating disorders, such as bulimia nervosa or anorexia nervosa. Future studies should determine the DEBQf dimensions that need to be targeted to improve weight evolution, psychiatric and medical comorbidities, as well as health-related quality of life in these populations.

Disclosure of interest: I Rabemampianina, G Apfeldorfer, N Ballon, C Couet, C Réveillère, P Gaillard, W ElHage declare that they have no conflicts of interest concerning this article. P Brunault declares the following conflict of interest: financial support from Astra Zeneca to speak at one medical meeting (2014).

\section{References}

[1] Rapport Obépi-Roche 2012: Enquête épidémiologique nationale sur le surpoids et l'obésité. Available at: http://www.roche.fr/content/dam/corporate/roche_fr/doc/obepi_2012.pdf

[2] Petry N, Barry D, Pietrzak R, Wagner J. Overweight and obesity are associated with psychiatric disorders: results from the National Epidemiologic Survey on Alcohol and Related Conditions. Psychosom Med 2008;70:288-97.

[3] Peeters A, Barendregt JJ, Willekens F, Mackenbach JP, Al Mamun A, Bonneux L, et al. Obesity in adulthood and its consequences for life expectancy: a life-table analysis. Ann Intern Med 2003;138:24-32.

[4] Sonneville KR, Horton NJ, Micali N, Crosby RD, Swanson SA, Solmi F, et al. Longitudinal associations between binge eating and overeating and adverse outcomes among adolescents and young adults: Does loss of control matter? JAMA Pediatr 2013;167:149-55. doi:10.1001/2013.jamapediatrics.12.

[5] Corsica JA, Pelchat ML. Food addiction: true or false? Curr Opin Gastroenterol 2010;26:165-9. doi:10.1097/MOG.0b013e328336528d.

[6] Gearhardt AN, Corbin WR, Brownell KD. Preliminary validation of the Yale Food Addiction Scale. Appetite 2009;52:430-6. doi:10.1016/j.appet.2008.12.003.

[7] Brunault P, Ballon N, Gaillard P, Réveillère C, Courtois R. Validation of the French version of the Yale Food Addiction Scale: an examination of its factor structure, reliability, and construct validity in a nonclinical sample. Can J Psychiatry 2014;59:276-84. doi:PMCID: PMC4079141.

[8] Meule A, Vögele C, Kübler A. German translation and validation of the Yale Food Addiction Scale. Diagnostica 2012;58:115-26.

[9] Van Strien T, Frijters JE, Bergers G, Defares PB. The Dutch Eating Behavior Questionnaire (DEBQ) for assessment of restrained, emotional, and external eating behavior. Int J Eat Disord 1986;5:295-315.

[10] Bruch H. Eating disorders: Obesity, anorexia nervosa, and the person within. New-York: Basic Books; 1973.

[11] Kaplan H, Kaplan H. The psychosomatic concept of obesity. J Nerv Ment Dis 1957;125:181-201.

[12] Schachter S. Some extraordinary facts about obese humans and rats. Am Psychol 1971;26:129-44. doi: $10.1037 / \mathrm{h} 0030817$.

[13] Rodin J. Current status of the internal-external hypothesis for obesity: What went wrong? Am Psychol 1981;36:361-72. doi:10.1037/0003-066X.36.4.361.

[14] Davis C, Carter JC. Compulsive overeating as an addiction disorder. A review of theory and evidence. Appetite 2009;53:1-8.

[15] Apfeldorfer G, Zermati JP. [Cognitive restraint in obesity. History of ideas, clinical description]. Presse Médicale 2001;30:1575-80.

[16] Lluch A, Kahn J, Stricker-Krongrad A, Ziegler O, Drouin P, Méjean L. Internal validation of a French version of the Dutch eating behaviour questionnaire. Eur Psychiatry 1996;11:198-203. 
[17] De Lauzon B, Romon M, Deschamps V, Lafay L, Borys J-M, Karlsson J, et al. The Three-Factor Eating Questionnaire-R18 is able to distinguish among different eating patterns in a general population. J Nutr 2004;134:2372-80.

[18] Cappelleri JC, Bushmakin AG, Gerber RA, Leidy NK, Sexton CC, Lowe MR, et al. Psychometric analysis of the Three-Factor Eating Questionnaire-R21: results from a large diverse sample of obese and nonobese participants. Int J Obes 2005 2009;33:611-20. doi:10.1038/ijo.2009.74.

[19] Cook DA, Beckman TJ. Current concepts in validity and reliability for psychometric instruments: theory and application. Am J Med 2006;119:166.e7-16. doi:10.1016/j.amjmed.2005.10.036.

[20] Muthén B, Kaplan D. A comparison of some methodologies for the factor analysis of non-normal Likert variables. Br J Math Stat Psychol 1985;38:171-89.

[21] R Development Core Team. R: A language and environment for statistical computing. 2012.

[22] Revelle W. Psych: procedures for personality and psychological research. Version 1.3.10 [Internet]. Evanston (IL): Northwestern University. Available from: http://CRAN.R-project.org/package=psych. 2013.

[23] Fox J. polycor: Polychoric and Polyserial Correlations. version 0.7-8. Available from: http://cran.rproject.org/web/packages/polycor/polycor.pdf. 2010.

[24] Hudson JI, Hiripi E, Pope HG Jr, Kessler RC. The prevalence and correlates of eating disorders in the National Comorbidity Survey Replication. Biol Psychiatry 2007;61:348-58. doi:10.1016/j.biopsych.2006.03.040.

[25] Piccinelli M, Wilkinson G. Gender differences in depression Critical review. Br J Psychiatry 2000;177:486-92. doi:10.1192/bjp.177.6.486.

[26] Rippe JM, Crossley S, Ringer R. Obesity as a Chronic Disease: Modern Medical and Lifestyle Management. J Am Diet Assoc 1998;98:S9-15. doi:10.1016/S0002-8223(98)00704-4.

[27] Thomas JG, Bond DS, Phelan S, Hill JO, Wing RR. Weight-Loss Maintenance for 10 Years in the National Weight Control Registry. Am J Prev Med 2014;46:17-23. doi:10.1016/j.amepre.2013.08.019.

[28] Basdevant A. Médecine et chirurgie de l’obésité. Paris: Lavoisier; 2011.

[29] Perez M, Warren CS. The relationship between quality of life, binge-eating disorder, and obesity status in an ethnically diverse sample. Obes Silver Spring 2012;20:879-85. doi:10.1038/oby.2011.89.

[30] Andersen JR, Aasprang A, Bergsholm P, Sletteskog N, Våge V, Natvig GK. Predictors for healthrelated quality of life in patients accepted for bariatric surgery. Surg Obes Relat Dis 2009;5:329-33. doi:10.1016/j.soard.2008.11.012.

\section{FIGURES}

Figure 1. Scree plot and parallel analysis for normal weight people.

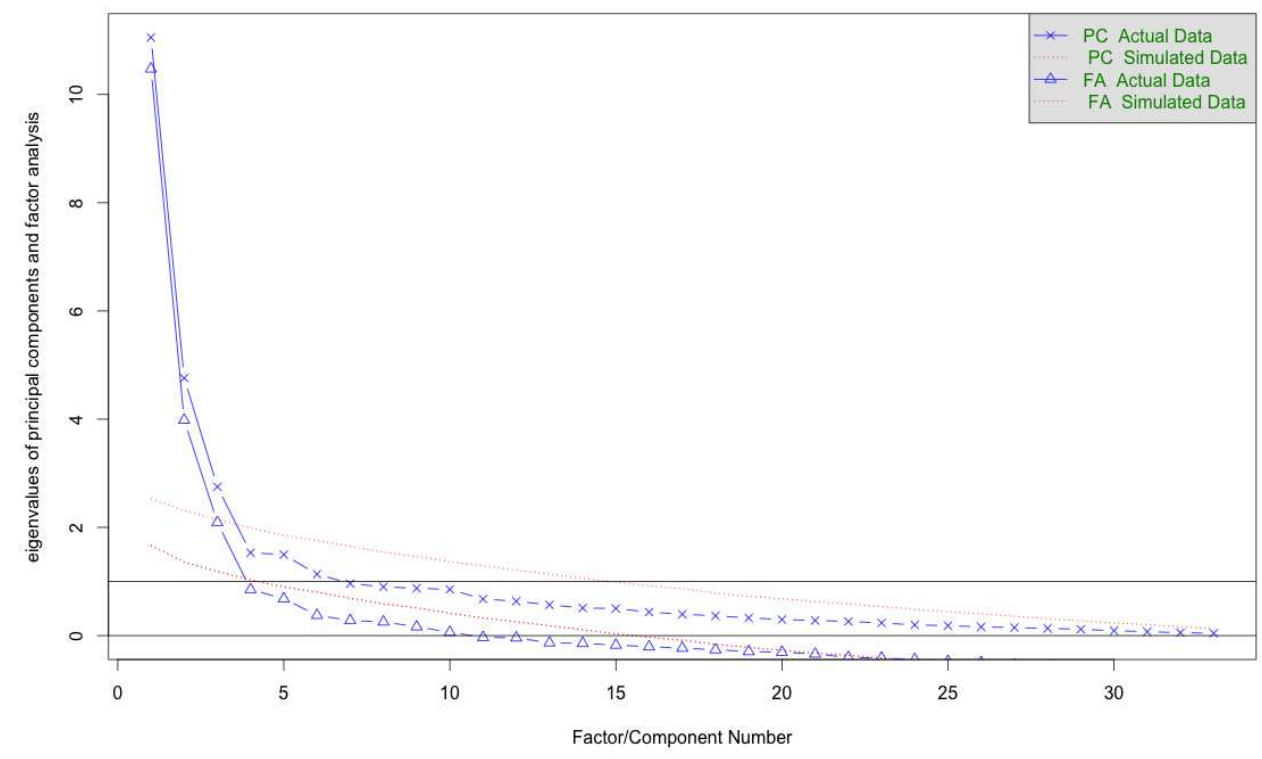


Figure 2. Scree plot and parallel analysis for obese patients.

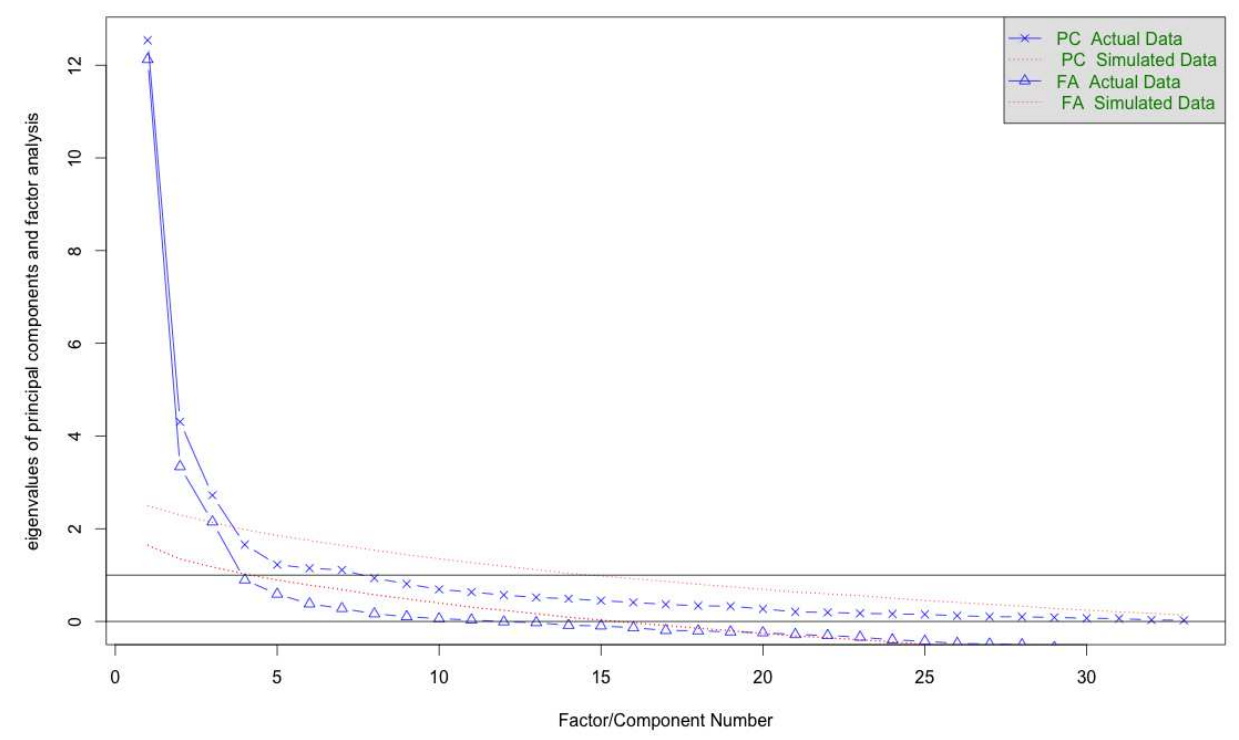




\section{TABLES}

Table I. Variables associated with DEBQ scores (correlations)

\begin{tabular}{|c|c|c|c|c|}
\hline & Age & $\begin{array}{c}\text { Current } \\
\text { BMI }\end{array}$ & $\begin{array}{c}\text { Previous } \\
\text { maximal } \\
\text { weight loss }\end{array}$ & $\begin{array}{l}\text { Holmes \& } \\
\text { Rahe score }\end{array}$ \\
\hline \multicolumn{5}{|c|}{ In the whole population } \\
\hline Emotionality & $\mathrm{r}=-0.12$ & $\mathrm{r}=0.21^{*}$ & $\mathrm{r}=0.12$ & $r=-0.03$ \\
\hline Diffuse & $r=-0.17^{*}$ & $\mathrm{r}=0.15$ & $r=0.08$ & $r=-0.01$ \\
\hline Defined & $r=-0.09$ & $\mathrm{r}=0.21^{*}$ & $\mathrm{r}=0.13$ & $\mathrm{r}=-0.03$ \\
\hline $\begin{array}{l}\text { Cognitive } \\
\text { restraint }\end{array}$ & $\mathrm{r}=-0.47^{* * * *}$ & $\mathrm{r}=0.29^{* * *}$ & $\mathbf{r}=\mathbf{0 . 3 0} 0^{* * *}$ & $\mathrm{r}=0.07$ \\
\hline Externality & $r=0.21^{* *}$ & $r=-0.20^{*}$ & $\mathrm{r}=-0.12$ & $\mathrm{r}=-0.07$ \\
\hline \multicolumn{5}{|l|}{ In obese patients } \\
\hline Emotionality & $\mathrm{r}=-0.18$ & $\mathrm{r}=0.24^{*}$ & $\mathrm{r}=0.06$ & $\mathrm{r}=-0.11$ \\
\hline Diffuse & $r=-0.28^{*}$ & $r=0.36^{* *}$ & $\mathrm{r}=0.08$ & $r=-0.07$ \\
\hline Defined & $\mathrm{r}=-0.14$ & $\mathrm{r}=0.18$ & $r=0.04$ & $\mathrm{r}=-0.11$ \\
\hline $\begin{array}{l}\text { Cognitive } \\
\text { restraint }\end{array}$ & $\mathrm{r}=0.14$ & $\mathrm{r}=0.12$ & $r=0.16$ & $r=-0.10$ \\
\hline Externality & $r=-0.40^{* * *}$ & $\mathrm{r}=-0.14$ & $\mathrm{r}=0.15$ & $\mathrm{r}=-0.02$ \\
\hline \multicolumn{5}{|c|}{$\begin{array}{l}\text { BMI: Body Mass Index. Holmes \&Rahe score: total score according to Holmes \&Rahe stress scale. } \\
\text { r: Spearman'scorrelation coefficient. *** } p<0.001 ; * * p<0.01 ; * p<0.05 ; n s: \text { non significant. } \\
\text { Significant associations are indicated in bold fonts. }\end{array}$} \\
\hline
\end{tabular}


Table II. Factor loadings for each DEBQf item for normal weight persons (three-factor model with varimax rotation)

Eigenvalue

Percent of variance explained

$\begin{array}{ccc}\text { Factor } 1 & \text { Factor } 2 & \text { Factor } 3 \\ 6.31 & 6.15 & 4.69 \\ 19.1 \% & 18.6 \% & 14.2 \%\end{array}$

Emotionality

Item 1.

Item 5.

Item 10.

Item 13.

Item 16.

Item 20.

Item 23.

Item 25.

Item 30.

Item 32.

\section{Cognitive restraint}

Item 4.

Item 7.

Item 11.

Item 14.

Item 17.

Item 19.

Item 22.

Item 26.

Item 29.

Item 31 .

Externality

Item 2.

Item 3.

Item 6.

Item 8.

Item 9.

Item 12.

Item 15.

Item 18.

Item 21.

Item 24.

Item 27.

Item 28.

Item 33.
0.78

0.68

0.58

0.73

0.70

0.84

0.83

0.71

0.84

0.73

0.13

0.19

0.77

0.70

0.32

0.59

0.67

0.10

0.13

0.15

0.18

0.16

0.76

0.61

0.86

0.66

0.73

0.71

0.18

0.27

0.18

0.30

0.14

0.19

0.19

-

0.16

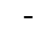

$-$

0.34
0.12

0.39

0.10

0.27

0.11

0.32

0.16

0.26

0.24

0.29

0.26

0.13

0.20

0.22

0.20

0.15

0.27

0.14

0.21

-

$-0.12$

-

-

-

-

-: indicates a factor loading lower than 0.10. 
Table III. Factor loadings for each DEBQf item for obese patients (three-factor model with varimax rotation)

Eigenvalue

Percent of variance explained

$\begin{array}{ccc}\text { Factor } 1 & \text { Factor } 2 & \text { Factor } 3 \\ 8.84 & 5.69 & 3.73 \\ 26.8 \% & 17.2 \% & 11.3 \%\end{array}$

Emotionality

Item 1.

Item 3.

Item 5.

Item 8.

Item 10.

Item 13.

Item 16.

Item 20.

Item 23.

Item 25.

Item 30.

Item 32 .

Cognitive restraint

Item 4.

Item 7.

Item 11.

Item 14.

Item 17.

Item 19.

Item 22.

Item 24.

Item 26.

Item 29.

Item 31 .

Externality

Item 2.

Item 6.

Item 9.

Item 12.

Item 15.

Item 18.

Item 21.

Item 27.

Item 28.

Item 33.

$\begin{array}{ll}\mathbf{0 . 8 5} & 0.13 \\ \mathbf{0 . 5 8} & 0.55 \\ \mathbf{0 . 8 0} & 0.32 \\ \mathbf{0 . 7 0} & 0.52 \\ \mathbf{0 . 7 7} & 0.37 \\ \mathbf{0 . 9 0} & 0.17 \\ \mathbf{0 . 6 8} & 0.23 \\ \mathbf{0 . 8 8} & 0.26 \\ \mathbf{0 . 8 8} & 0.29 \\ \mathbf{0 . 9 0} & 0.11 \\ \mathbf{0 . 8 4} & 0.27 \\ \mathbf{0 . 7 4} & 0.45\end{array}$

0.11

0.18

0.66

-

$-0.19$

0.55

0.21

0.26

0.52

- $\quad-0.30$

0.60

-

0.58

- $\quad 0.23$

0.60

$-0.10$

0.24

0.12

0.74

$-0.24$

0.60

0.41

0.70

0.16

0.82

0.10

0.83

0.30

0.67

0.43

0.55

0.21

0.58

$-0.10$

0.38

0.61

0.26

0.49

0.36

0.59

0.61

0.55

0.48

Underlined items correspond to items that do not belong to the same factors in normal weight and obese persons.

-: indicates a factor loading lower than 0.10. 